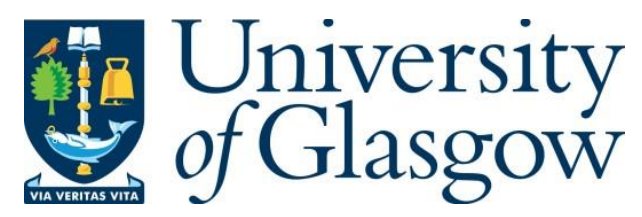

Hersh, M. and Elley, S. (2019) Barriers and enablers of inclusion for young autistic learners. Advances in Autism, 5(2), pp. 117-130.

There may be differences between this version and the published version. You are advised to consult the publisher's version if you wish to cite from it.

http://eprints.gla.ac.uk/178550/

Deposited on: 12 February 2019

Enlighten - Research publications by members of the University of Glasgow http://eprints.gla.ac.uk 


\title{
Barriers and Enablers of Inclusion for Young Autistic Learners: Lessons from the Polish Experiences of Teachers and Related Professionals
}

\begin{abstract}
This paper presents new empirical data on the experiences of 120 teachers and professionals working with autistic children and young people across different settings in Poland where autism research on inclusive education is scarce. It uses a survey approach involving a combination of qualitative and quantitative data collection and embeds practical findings in theory, including the relationship of inclusive education to the social and neurodiversity models of disability. Polish teachers' attitudes, experiences and support needs, including some previously overlooked issues are related to the broader international context beyond Poland. Analysis of the findings is used to derive evidence-based recommendations for good practice and modelling, and evaluating future education and inclusion practices. These recommendations include opportunities to exercise responsibilities and take leadership roles; social as well as educational inclusion; provision of a safe environment; regular funded autism training in work time; and appropriate use of additional classroom teachers.
\end{abstract}

\section{Key words}

Autism, Inclusion, Learning, Teaching, Education, Teachers, Professionals, Poland, International.

\section{Introduction: the study context}

Worldwide, research suggests that $0.62 \%$ of people are autistic with slight variations across countries e.g.. $1.47 \%$ of US children, $1.1 \%$ of UK children, and $0.34 \%$ of Polish children formally diagnosed, with further tens of millions including families (in)directly influenced (Piskorz-Ogórek, et al., 2015; Wee, 2017). Despite 20 years of progress, there are still many unresolved educational issues, including a lack of good programmes, qualified staff and integrated or inclusive teaching provision. Recently, educational inclusion has succeeded integration in Europe and elsewhere. However, inclusive practice remains difficult (e.g. Emam and Farrell, 2009). Facilitating inclusive educational practices which meet the individual needs of autistic children and the relationship between inclusive educational practices, learning and teachers experiences remain under-researched in the Polish context.

Autism spectrum 'disorders' (ASD) are defined by the medical model as a set of complex neurological developmental conditions (ICD-10), leading to intellectual and behavioural challenges throughout life. According to the social model of disability (Barnes, 1994) and the compatible neurodiversity model (Davidson and Orsini, 2013) people on the autistic spectrum experience social, attitudinal and infrastructural barriers and frequently social exclusion (e.g. Humphrey and Lewis, 2008). This is often compounded by non-autistic people's lack of understanding and acceptance of 'autistic' differences in thinking, moving, interacting, and sensory and cognitive processing, and deficit-based 'labelling' and terminology. The term autistic people will be used subsequently for everyone on the autistic spectrum including those with Asperger's syndrome, as the term commonly preferred by many autistic people. 
However, the closest equivalent translation will be used in the empirical data from Poland.

Following adoption of the UN Convention on the Rights of People with Disabilities (2006) Poland has attempted to move from a medical-social model of disability to a social model (Barnes, 1994). However, this has had mixed success in raising the quality of education provision and there are still barriers to inclusive education. This research project chose to study approaches to the inclusion of autistic students through the Polish experience for several reasons. Inclusive education is central to the "Education For All" (EFA) and European Union agenda for change. There is value and a need to move outside English speaking countries and fill the gap in research on Eastern Europe. Most autistic and other disabled students (76\%) are still in 'special' (segregated) education in Poland (Author 1 et al., 2014) but there are promising indications of some movement towards inclusion.

Concepts of inclusion are generally less well known in Poland than the UK and integration often dominates educational thinking (Starczewska et al., 2012). Compulsory education in Poland starts in preschool aged 5 and at the time of the study was followed by primary school (6/7-13), lower secondary (13-16) and upper secondary (16-19) or vocational school (15-18). Education reforms in 2017 extended primary school to age 15 and removed lower secondary. In the UK, greater progress means ' ... pupils with special educational needs should wherever possible receive their education in a mainstream school' (DfEE, 1997: 2). Inclusion, but not integration, requires restructuring all mainstream schools across the curriculum so every child, disabled or not, fully participates in schooling, learning and communities. Avramidis and Norwich (2002: 192) suggest '. . . inclusion therefore becomes part of a broad human rights agenda that argues that all forms of segregation are morally wrong' and Buława-Halasz (2015) claims 'it is not the child, but the system which needs to change'. Indeed, Article 70 of the Constitution of the Republic of Poland 1997 states that 'Everyone shall have the right to education. [. . .] Public authorities shall ensure universal and equal access to education for citizens.' Yet, research in this area often fails to give a nuanced picture of the experiences of autistic pupils and relevant professionals with most research instead focussing on other groups of disabled pupils in Poland.

There is increasing recognition of the benefits of inclusive education to both (non) disabled and autistic students (Martin and Milton, 2017) worldwide but no clear definition of its meaning, process or best practice. In Poland, the Polish European Agency for Special Needs and Inclusive Education (undated,a) provides guidance on best practice which aims to: 1) raise learner achievements by recognising and building on their talents, skills and meeting their individual learning needs and interests; 2) provide personalised approaches that engage all learners and support their active learning participation; 3 ) ensure all stakeholders value diversity and contribute individually and collectively to widening educational access; 4) enable stakeholders to develop inclusive attitudes and beliefs, knowledge, understanding, skills and behaviours and learning engagement at both individual and organisational levels; and 5) work towards continuous improvement through capacity building and collectively shared goals. Our research project is informed by this 'vision' of inclusive education and the limited literature and research findings on inclusive education for autistic students. 
General disability research suggests slow progress with disabled students sometimes isolated or otherwise disadvantaged in mainstream classrooms or segregated schooling. The Polish European Agency (undated,b) also claims that students with 'special educational needs' are often, for example, discouraged from attending mainstream schools; special schools increasingly mainly attract pupils with multiple impairments; and anxiety about change makes special school teachers resistant to integration/inclusion. Some parents may try to 'normalise' their disabled child via mainstream school attendance, often in schools unable to meet complex individual needs. There is frequently insufficient recognition of the need for measures to ensure social, as well as educational inclusion. This can be particularly important and difficult for autistic students and, consequently, there is a need to develop wellresourced mainstream education for all children. Grounded in empirical data and the social model of disability, our research offers new insight into the Polish education context and professionals' lived experiences of working with autistic children and young people, and highlights the barriers, enablers and facilitators of educational inclusion for autistic children and their application within, and beyond, Poland.

\section{Literature Review}

The growing use of mainstream education e.g. (Avramidis and Norwich, 2002) for autistic children makes the issues associated with effective teaching, learning and support relevant to all teachers worldwide. There is also serious concern about the future education and employment prospects of autistic people, with an estimated 12$15 \%$ of higher functioning UK individuals in paid employment and only $25 \%$ of young autistic adults having any education or training after school (Touhig, 2013). Research in this area is sparse, with few surveys of teachers or other education professionals, despite recognition of their crucial role in ensuring 'equal opportunities for quality education' and 'equity in treatment' (Donnelly and Watkins, 2011). Relatively few success factors have been identified. This section provides an overview of research on education provision and experiences in various countries with a focus on the factors that effect inclusion of autistic learners.

There are three main models for educating disabled students: 'segregation' in (non) residential special schools; 'integration' in mainstream schools in inclusive or special classes, but often 'the onus is on the assimilating [disabled] individual...to make changes so they can 'fit in" (Frederickson and Cline, 2002: 65); and, 'inclusion' in age appropriate mainstream classes in mainstream schools with appropriate support and aids and 'the onus is on the school to change, adapting curricula, methods and procedures so that it becomes more responsive' (Frederickson and Cline, 2002: 65; Buława-Halasz, 2015 ). International research shows that 'special' school teachers generally have more autism training and better support than mainstream teachers, with only a very small minority of US mainstream teachers feeling 'well-prepared' to teach autistic pupils (Teffs and Whitbread, 2009). This raises issues of how this expertise can be transferred from special to inclusive education.

A Scottish study found it can take teachers up to a year to feel competent to teach an autistic child (Glashan et al., 2004). Full and half-day workshops were the most frequently used training approach in a US survey, followed by practical experience of working with autistic students and self-training (Morrier et al., 2011). However, ongoing technical assistance and access to resources to support training are 
recommended (Scheuerman et al., 2003). Generally, teachers in Poland experience particular difficulties in dealing with the different social and emotional understanding and communication styles of autistic and non-autistic students, motivating autistic students, tackling 'challenging' behaviour (Urbanovská et al., 2014) and often lack time to meet individual students' needs.

Interventions in the UK and USA are increasingly being tailored to individual children in line with literature showing the value of individualised goals, strategies and evaluation criteria (Hume et al., 2012; Martin and Milton, 2017). This includes joinedup and consistent approaches across parents, teachers and therapists (Ruble and Dalrymple, 2002). Individual approaches to assessment, joint work with parents (Korulska, 2013) and individual approaches which take account of various student features have also been recommended in Poland (Garnkarz and Rybka, 2012), but it is unclear to what extent they are applied in practice. Head teachers' social/medical model orientation and attitudes toward inclusive classrooms have been found to be the main predictor of effective teaching (Stanovich and Jordan, 1998). 'Social model' teachers often teach more effectively and inclusively than 'medical model' teachers (Stanovich and Jordan, 1998), indicating the importance of educating teachers about the social model of disability. Experience of teaching an autistic child has also been shown to increase positive attitudes to integration (McGregor and Campbell, 2001; Teffs and Whitbread, 2009).

Additionally, experience of autism has been found to be crucial for supporting autistic children and their teachers, but is generally lacking (Glashan et al., 2004). However, teachers generally have positive attitudes towards autistic children, with younger and female teachers, and those who had attended multiple autism workshops having more positive attitudes (Park and Chitiyo, 2011). However, US head teachers have problematically been found to recommend lower levels of inclusion for 'socially detached' autistic students and higher levels for good academic performers, with most teachers preferring the support of an additional teaching assistant (Giancreco et al., 1999).

Studies show that many assistants have little or no autism specific training and often little knowledge of the school rules (Glashan et al., 2004), although many had taken courses or researched the topic in their own time and shown considerable commitment (Glashan et al., 2004). Some studies show that the presence of an assistant can damage the teacher-student relationship and reduce interaction with the teacher (Giancreco et al., 1997). This may be avoided by the teacher and assistant sharing responsibility for the autistic student and developing strategies together (Teffs and Whitbread, 2009).

There is currently a small body of literature on inclusive education of autistic children, with only a few studies in Poland, sometimes in the context of inclusive education more generally. Research studies globally indicate numerous common issues in working with autistic children and young people across different educational settings to facilitate inclusion, which require further research and investigation. There are also a number of recommendations for good practice, drawn both from the Polish context and internationally. They include the importance of a social model perspective, particularly from the head teacher, experiences of autism and the need for training, but have limited scope and are dispersed across the literature. 
Most of the literature is from English speaking countries and there is minimal literature from the perspective of teachers or from a social model/neurodiversity perspective, particularly in the Polish context. The limited literature in the Polish context often focuses on 'therapy' rather than education. Some of the recommendations draw on research involving only a very small number of autistic children and in some cases their derivation from the underlying research has not been explained. This paper aims to fill some of these gaps and advance understanding by investigating inclusive education for autistic children in Poland. It is embedded in the social model of disability, the Polish European Agency vision of inclusive education, and a research strategy as discussed next.

\section{Methodology}

The research used a survey of teachers and education professionals working with autistic students to broadly investigate:

1. What is the current state of inclusive education for autistic students in Poland?

2. How does existing practice relate to theory?

3. How can experience and good practice of working with autistic students be generalised from special to mainstream/inclusive education?

4. What are the enablers and barriers to inclusive practice?

5. What are the lessons from Poland for other countries in the process of moving towards inclusive education?

The theoretical analytical framework was based on the social model of disability. The survey approach enabled the collection of quantitative data and investigation of its statistical significance (not reported here due to space considerations) and qualitative accounts capturing the richness of personal experience Ethical considerations were central to the study design and throughout the research process. Ethical approval was obtained from the University of Glasgow College of Science and Engineering Ethics Committee. In line with ethical procedures, completion of the questionnaire was voluntary, all of the responses were submitted anonymously and participant confidentiality and data protection were assured. The first page of the questionnaire included an information sheet explaining the research.

The first section of the two-part questionnaire covered personal information for statistical correlation purposes, including gender, profession, main place of work, years of experience and the main subjects taught and/or the main areas of professional expertise. The second section collected quantitative and qualitative data on topics such as working with autistic, including nonverbal, students, additional teachers and training. Rating scale questions investigated the importance of both various issues in work with autistic students and suggestions for support. Further open questions investigated difficulties and good practice in working with autistic students. Since full inclusion should affect all aspects of education and to avoid biasing the results, there was no explicit mention of inclusion in the questionnaire. This allowed inclusive and non-inclusive practices to emerge naturally from participant responses.

Quantitative data analysis used calculation of percentages and the average value for the rating scales. The quantitative data was merged with the qualitative data 
(although not presented here due to space constraints). Analysis of the qualitative data was carried out without translation and only the chosen quotes were translated (by the first author).

Qualitative data analysis followed a interpretivist thematic approach which allows for a nuanced and complex understanding of data. A thematic content analysis was carried out (Joffe and Yardley, 2004). This meant moving from a description of the data to emerging themes and analysis, and then the broader implications of the data. First-order themes arose out of the data without a predetermined reference framework to capture the essence of the data and delimit bias (Boyatzis, 1998; Braun and Clark, 2006). These were then reorganised into groups via second-order coding. Sub-themes via data interpretation led to overarching themes around enablers, barriers, inclusion and exclusion. Thematic analysis of these identified several subthemes as discussed in the results below, however, due to space constraints, mostly responses to open-ended questions are presented.

The methodological strengths of the project include the combined approach as both quantitative descriptive statistics and qualitative thematic analysis enabled a more robust and comprehensive understanding of the research problem, setting, context and language/experiences than either approach alone. Merging the two data sets also minimised researcher bias and enabled the collection of more data than, say, just interviews. This meant combining deductive and inductive thinking, and analysing the qualitative findings to validate the quantitative responses. Other strengths of the project include its originality, research on a rarely studied population, well formulated research questions derived from a thorough investigation of the literature and timeliness related to debates on education and inclusion including Poland's transitional status.

Limitations of the study include the relatively small sample size, though category saturatation was achieved, and the sampling approach via accessing workshops, possibly leading to bias towards more interested and motivated participants. Resources permitting, the project would also have supplemented the data gathered with individual interviews. Nonetheless, the study was theoretically informed, empirically grounded and collected robust data in order to capture meaningful patterns of experiences and views to generate an in-depth analytical understanding of inclusion practices in Poland.

\section{Results and Discussion 4.1 Overview}

In total, 121 responses were received, 115 at workshops and other events and six electronically. 120 useful responses remained after discarding one not from a teacher or other education professional. Participants represented the diversity of roles across the sector with regards to location, profession and experience, though the greatest numbers were primary and preschool teachers $(36.4 \%)$, followed by educational therapists (19.4\%). Two thirds worked in preschool $(21.2 \%)$, primary (33.1\%) and secondary schools (12.7\%). Other locations included clinics (12.7\%) and therapy centres (11.9\%). The large majority of female participants $(91.7 \%)$ follows the gender distribution in the sector and other surveys e.g. (McGregor and 
Campbell, 2001). The majority of school-based respondents worked in special schools $(57.9 \%)$, with only $15.8 \%$ in mainstream schools and $6.6 \%$ in mainstream and integrated schools. This indicates that, at least at pre- and primary school level, the majority of autistic children in Poland were in special schools. It adds to the picture of the extent of inclusion and integration worldwide, confirms evidence in Author 1 (2014) on the state of educational inclusion in Poland and shows Poland is not (yet) a 'mainstreaming' country like Scotland and USA (McGregor and Campbell, 2001; Teffs and Whitbread, 2009). The research also adds the perspective of a teachers and other educational professionals in a country where special education for autistic children is still the expectation.

The majority of respondents were currently working with autistic students (86.7\%), with a small number having done so in previous, but not the current year $(8.3 \%)$. Three quarters $(74.8 \%)$ had worked with non-verbal autistic people. Respondents most commonly worked with 2-5 autistic children and young people (40\%). Just over half of respondents had a teaching assistant and nearly $40 \%$ did not, with small numbers having one 'sometimes' or 'rarely'. This seems lower than current literature suggests, possibly due to the relatively poor economic situation in Poland. In about a third of 22 replies, the assistant supported only autistic children, whereas about two thirds supported both autistic and other disabled children. In the majority of 19 replies, the assistant supported a small group of 2-5 students. In nearly $60 \%$ of 31 responses, the assistant was present at all classes, in about a sixth of cases only at academic lessons and in nearly $10 \%$ for about half the teaching time. Limited or no attention has previously been given to the circumstances of provision of additional teachers or assistants.

\subsection{Communication}

Communication was considered important by over half the participants, 'difficult' by over a quarter and nearly a fifth made suggestions for good practice. This is in line with current surveys showing communication is one of the most demanding issues for participants (Urbanovská et al., 2014). Appropriate communication strategies are clearly important for inclusion. However, non-autistic and autistic people may have different attitudes to communicating and engaging in dialogue which can affect inclusion and require special strategies.

Many participants focused on finding an effective form of communication, with comments including 'to find a method of communication that is accepted by the autistic person' and 'developing points of communication, so the autistic person feels less frustrated'. Difficulties included developing appropriate communication systems, understanding needs and communication with non-verbal people, which was most highly scored in the closed evaluation of importance questions. Specific comments included 'reaching them in the case of serious autism' and 'expanding the types of communication suitable for autistic people and adapted to the way they think'. One respondent expanded with:

The child's inability to communicate his/her needs and wants ... instead of answering the question the child repeats it or gives all possible answers and lack of communication about their feelings. 
Participants had used a wide range of different communication methods with nonverbal autistic children, with many respondents using several different ones. This issue has received minimal discussion previously. The most popular approaches were graphical, in line with the literature on the effectiveness of interactive visual learning materials and cues with autistic students (Carnahan et al., 2009). Other popular approaches were gestures, Makaton and speech. Only three respondents used a national sign language. Many of these communication systems are most suitable for expressing basic needs, but less so for more complex communication. This is probably appropriate for pre- and primary school children, but could be restrictive later in life or act as a barrier to inclusive education, as students generally need to engage in increasingly complex communication as they progress.

Suggestions for good practice generally covered the use of communication systems for non-verbal students, in line with existing literature e.g. (Ganz et al., 2012). In many cases a particular communication system, such as PECS, PEC or pictograms, was mentioned without further comments. However, one respondent suggested 'classes with the support of non-verbal communication methods such as Makaton and PCS symbols'. Many of the comments showed an awareness of the child's perspective, empathy with probable feelings, and respect and recognition of the importance of a communication system appropriate to the particular child. Despite considerable discussion in the literature of communication with autistic students (e.g. Garncarz and Rybka, 2012), teachers' and other education professionals' views seem largely unreported.

\subsection{Training}

Just over $90 \%$ of participants had had some autism training. However, half of them had paid for it themselves, with the employer only paying part or all the costs in just over a third of cases. Very few had attended training fully or partially in work time. The majority had attended training outside work, and $10 \%$ had taken leave in order to do this. The high percentage of respondents who had attended training compared to the literature may be due to greater motivation and consequently willingness to pay themselves and attend in their own time. However, the recognised importance of training means that access to it should not be dependent on self-payment and attending outside work. Taking the possibility of bias towards more interested and knowlegeable respondents into account only strengthens this conclusion, as less interested teachers are unlikely to be willing to pay for training or to attend in their own time. Proposals for improving their understanding of autistic students included 'good contact with a lot of people with autism' and 'practice is important'.

Participants responses showed their interest in training, with regular training receiving the second highest score of the various proposed solutions and a large proportion of respondents $(21.3 \%)$ raising the need for more and better training. This agrees with the literature on the general lack of autism training despite high demand and perceived training needs (McGregor and Campbell, 2001; Teffs and Whitbread, 2009). Meeting other teachers and autistic adults, which can contribute to training, were also highly scored. Several participants wanted fully financed training, with 'a need for specific training courses teaching approaches for work with [autistic] students ..., coping with aggression and self-harm'; 'greater accessibility (including financially) of professional training for specialists...'; and 'a professional course on 
how to work with autistic people. Such courses are very expensive'. However, one teacher complained that 'it is very difficult in our school to motivate teachers to participate in training and workshops about autism'. This may have been explained by the need to pay for training themselves and attend outside working hours even though training often supports inclusive practices.

\subsection{Behaviour, Environment and Resources}

Specific behaviours and a lack of understanding of their causes were a significant source of difficulties. Aggression, self-harm and lack of social interaction were all considered very important and prevented class-room inclusion. This agrees with the literature (Glashan et al., 2004; Humphrey and Lewis, 2008; Urbanovská et al., 2014), although there do not seem to have been any analogous surveys previously. Behaviour also provided information, for instance 'to observe the child's behaviour in order to read from it what the child needs at a particular moment'. Teachers also recognised that 'difficult' behaviour was often a response to external circumstances:

Understanding the sources or stimulation which causes [aggression and selfharm]' and the student who is aware of his/her "otherness", but does not accept it. S/he does not want help...but at the same time gets angry when things don't work.

This led to responses of managing an inclusive environment, for instance 'removing or reducing sensory stimulation which causes difficult situations' and 'foresee situations in which the student will be oversensitive'. Recognition that behaviour is a way to communicate needs or a reaction to stimulation is in line with the literature on behaviour as communication about desires, needs, fears and concerns (Pietrowska, 2013). Teachers recognised that some of the difficulties they experienced were a consequence of their lack of knowledge and understanding of autism, for instance ' $I$ sometimes understand their untypical behaviour and understand them (and the causes)' and 'my very limited knowledge of autism'. They also expressed difficulties in 'recognising the needs of the child' and 'not knowing their preferences'. This raises issues of potential difficulties in inclusive education where teachers may have even less knowledge, training, and opportunity to learn from experience.

Specific comments on the teaching environment included the importance of 'an appropriately prepared place of work', 'ensure(ing) quiet and calm in the group', and 'adapting the environment as far as possible to the child's needs'. Generating an appropriate environment was difficult for teachers concerned about inclusive spaces. Thus, due to 'different sensory perceptions sometimes despite trying hard I cannot create an environment which is comfortable for them'. This parallels recognition of the value of adjusting the environment to reduce sensory overstimulation (e.g. Ruble and Dalrymple, 2002). A lack of resources also made it more difficult, for example 'money to adapt the room fully to work with the child. It's frustrating when I see that the child has potential, but the conditions are unfavourable (and there is no money to change this)'. Financial resources for support in the education of autistic children in Poland have been noted as a barrier in the literature (Buława-Halasz, 2015). The success of inclusion is likely to depend at least in part on the ability to create suitable 'quiet' environments for autistic students. This could be more difficult in a larger school, though more resources might be available. 
Resource problems were a reoccurring theme, including 'the impossibility of employing additional specialists ... help for the teacher, due to the lack of financial resources ... (despite the need)' and 'stress due to the limited organisational possibilities'. Additionally, the limited available resources were not always used effectively. For instance, 'the school system is not adapted to [autistic students'] needs'. While the lack of resources should not be used as a justification for not implementing inclusive education, the availability of sufficient and appropriate resources clearly facilitates inclusion.

\subsection{Social Interaction}

Several participants raised autistic students' relationships and social abilities, paralleling concerns in the literature about encouraging social interaction and developing social abilities e.g. (Glashan et al., 2004) to enhance inclusion This includes contact with teachers or other professionals and raises issues of the social dimension of educational inclusion. However, it is important to avoiding assumptions about frequency and type of socialising or pressurise autistic students to socialise.

Suggestions for developing social skills, included 'helping autistic people understand the system of social obligations' and 'preparation for managing in a social group (to the extent of their possibilities)'. On the negative side 'the inability to follow group rules and norms' was considered a difficulty. Recommendations for good practice included peer group involvement, for example:

We introduced a buddy system into classes with autistic students. The neurotypical students looked after the autistic children, in classes they invited them to take part in group work, they spent the breaks with them. ... the neurotypical students themselves understood the sense and the need for such a system.

Other approaches were based on educating non-disabled children and inclusive approaches to teaching social skills, including 'teaching the children how to understand the child with autism ... what his or her behaviour means, how to play with that colleague etc.' and 'lessons in small groups (2-3 children) for autistic and non-disabled children about social abilities and communication'. This last proposal indicates the potential for autistic and non-disabled students to learn from each other and develop social strategies and interactions that work for both groups and draw on their strengths. All these approaches go beyond the pure physical presence of autistic students in the classroom and encourage their active inclusion and participation in class activities.

\subsection{Integration and Inclusion}

Several participants showed an interest in encouraging integration. Suggestions for good practice leading to integration included 'total integration as its lacking' and 'continuing integration of autistic children from preschool to school'. Participants frequently focused on inclusive social events, such as: 
Common socials and outings for students with and without autism, betweenclass social events for children with different degrees of disability, integrating social events for students from our school and the mainstream school.

Other suggestions related to giving autistic students a role and responsibilities, for example:

Including the student in the life of the class, asking what s/he thinks about particular initiatives, entrusting him/her with certain responsibilities ... selecting the student as team captain ..., engagement in class plays etc.

The suggestion for making autistic students team captain is particularly interesting, as it is suggested that team selection is a type of activity to be avoided, as it often leads to exclusion (Williams et al., 2005). With appropriate support and resources, giving autistic students roles and responsibilities could counter stereotypes, develop social skills and maximise strengths and inclusion. While the need to 'prepare nondisabled students for "otherness", including for contact with non-verbal autistic students' was noted, one teacher considered that 'the students who are in classes with autistic students are tolerant, friendly, caring to them'. This follows a recommendation in the Polish literature on the importance of tolerance and openness by students and staff (Korulska, 2013). However, acceptance and respect would be preferable to tolerance. A related issue was the need for autistic children to feel safe and comfortable, including 'respect (for classmates)'; 'the widest possible understanding ... by society to avoid them being objects' and 'ensuring acceptance and...feelings of safety for the child'. To achieve this, respondents typically suggested additional teachers or assistants which received their highest score of the various proposed solutions. This parallels teachers' preferences in the literature for a teaching assistant (Giancreco et al., 1997).

Assistants were considered necessary for non-academic as well as academic classes, as 'the fact that students do not need to sit on a bench during gymnastics classes does not mean that an autistic student does not suddenly lose control in front of the other students'. In some areas, organisational polices prevented the employment of assistants. 'In my preschool the mothers employed [an assistant], (using a loophole in the rules).... in other schools an autistic person would not have this possibility.' In some cases, assistants were not employed even when resources were available. 'Every school receives a large subsidy for children with autism, but when they cause problems, instead of employing an assistant, they are pushed out of school'.

\section{Inclusive Practice}

While nearly $60 \%$ of respondents worked in special schools and only just under a quarter in mainstream (and integrated) schools, participants provided a number of examples of inclusive practice. These included buddying systems and giving autistic students responsibilities, such as team captain. Several participants showed attitudes compatible with inclusion. In particular, they tried to understand the perspective of autistic students and their reasons for their behaviour rather than blaming them for 'difficult' behaviours. Thus, while there is still relatively limited 
physical inclusion in Poland, attitudes and practices are frequently compatible with inclusion.

The barriers to inclusive practice include barriers to both moving autistic students to mainstream schools and ensuring inclusion within a particular school. The survey investigated the latter. Barriers identified include accessing training, difficulties in understanding autistic perspectives and needs, and communicating with them, lack of resources and organisational structures. Overcoming the barriers to accessing training will require costs to be covered and participation during work time. However, it is not just access to training, but its content and underlying philosophy which are important. In particular, research shows the importance of the social model in supporting inclusion (Stanovich and Jordan, 1998). Practitioners in Poland have recently become aware of and started to adapt the social model (Pasterny, 2017). However, even where the social model is recognised in institutional policies, the medical model frequently still dominates in practice. Thus, training should include the social model and its implications and encourage culture change.

The difficulties teachers experience in communicating with and understanding autistic students highlight some of the barriers to inclusion and are the other side of English autistic students concerns that their teachers lack understanding of them (Humphrey and Lewis, 2008). Currently, mainly non-autistic teachers teach autistic (and other) students. There is therefore a need to investigate the barriers to autistic people becoming teachers and implement measures to overcome them. Although each autistic person is very much an individual, autistic adults are a potential source of expertise, able to offer lived experiences of communication issues and insight into the perspectives of autistic students, making increased contact and discussion with them helpful.

Facilitators of inclusion include the very positive attitudes of teachers, their willingness to understand autistic students' perspectives and inclusive practices, including provision of quiet environments (Ruble and Dalrymple, 2002) and small group teaching. Approaches already used to support inclusion include buddy systems and allocating responsibilities such as team captain. If used appropriately, this can transform class dynamics and perceptions of autistic students across a wide range of professionals.

Lessons from Poland for other countries in transition to inclusive education include the need for an appropriate understanding of inclusion. It is therefore suggested that models or evaluation of the educational inclusion of autistic and (other minority group) students include:

- Opportunities to exercise responsibilities and take leadership roles;

- Social as well as educational inclusion and the development of enjoyable social opportunities for autistic students;

- Consultation with students and parents;

- Valuing diversity and focussing on the strengths rather than weaknesses of all students;

- Sensory 'quiet' environments.

In relating participants' experiences to theories of educational inclusion and understandings of autism, it is useful to note that: (i) the three main educational 
models of segregation, integration and inclusion; (ii) Poland is moving from segregation to inclusion; and (iii) educational provision is affected by medical, social or neurodiverse understanding of autism, with considerable overlap between the social model and neurodiversity.

Participants' experiences covered the full range from exclusion due to unwillingness to provide support and use available resources ('but when they cause problems, instead of employing an assistant, they are pushed out of school') to giving positions of responsibility ('selecting the student as team captain (in sport), engagement in class plays'). The first approach may be based in a deficit understanding of autism with the child seen as a source of 'problems' rather than alternatives based on neurodiversity and/or the social model of disability (Barnes, 1994). Neurodiversity would consider differences in understandings of the world, sensory and cognitive processing and sensory overstimulation as leading to differences in behaviour (Davidson and Orsini, 2013). Solutions would include providing an environment which supports the functioning of autistic students. The social model would look at social, attitudinal and infrastructural barriers and ways of overcoming them. Thus, despite their differences, neurodiversity and the social model are complementary and frequently lead to similar solutions.

Comments about 'respect' and making autistic children to feel 'safe' and 'comfortable' relate to both neurodiversity and the social model in recognising the barriers experienced and the need to overcome them. This is an advance on the recommendation of tolerance and openness in the Polish literature (Korulska, 2013). It is further seen in the need for 'the widest possible understanding of [autistic people] by society to avoid them being objects'. This may imply recognition of the need for a rejection of deficit models (autistic people as 'objects'). However, even though calls for understanding are positive, they tacitly imply what could be called the extreme differences of autistic people. Otherwise, this understanding would not be required. Discussion of managing the environment and 'removing or reducing sensory stimulation which causes difficult situations' recognise neurodiversity with its associated differences in the perceptions and responses of autistic and non-autistic people and the social model acceptance of the problems caused by barriers and removal of them.

Comments such as 'to find a method of communication that is accepted by the autistic person' and 'communication in different ways to get to the student' show that teachers recognise the existence of barriers to effective communication with and by autistic people and are taking responsibility for trying to overcome them in accordance with the social model. These comments also follow the neurodiversity perspective of recognising and respecting difference in thought and communication. However, comments on 'The child's inability to communicate his/her needs and wants' indicate a focus on 'deficits'. Thus, teachers should be educated about the social model to both challenge practices based on the medical model and enable those already using a social model approach to ground it in theory.

\section{Recommendations}


The following practical recommendations have resulted from the empirical survey data and literature and will better enable Poland's 'vision' of inclusive education for all:

\section{Supporting and teaching autistic students}

1. An individual teaching assistant or support teacher for each autistic student who provides effective support, but avoids gatekeeping their access to the teacher or other students;

2. Small group teaching and individual planning for autistic students, including individual motivation systems and transition support;

3. A positive, but realistic, attitude to each autistic student's academic and social potential and (pedagogical) approaches which draw on strengths and use (intense) interests.

\section{Provision of a safe environment for autistic students}

4. Minimising sensory disturbances and overstimulation in activities;

5. Inclusive climate where all (autistic) students feel safe and respected by all;

6. Contact or visits to schools by autistic adults acting as role models.

\section{Resources and inclusion}

7. Adequately funded schools and sufficiently high-quality resources to fully support quality teaching for (disabled) students;

8. Measures to promote inclusion: active involvement of non-disabled students, inclusive social events, opportunities for autistic students to take on roles and responsibilities;

\section{Training and information for professionals}

9. Regular funded training on working with autistic students with significant input from autistic adults;

10. Training, including (i) understanding autism from the perspective of autistic people; (ii) the social model of disability and neurodiversity (iii) communication with non-verbal autistic people; (iv) responding to 'challenging' behaviours.

\section{Concluding Comments}

This paper draws on the experiences of teachers and other education professionals working with autistic students in Poland to answer five important questions about educational inclusion of autistic students. Its significance includes evidence-based recommendations for good practice and a model of educational inclusion, applicable both within and beyond Poland. While paralleling the literature, the paper goes much further in relating teachers experiences of educational inclusion to different models of disability; raising issues not previously discussed and capturing the perspective of teachers and education professionals.

While the Polish government, like other countries, endorses the principles of inclusion embedded within a social model of disability, practical implementation has been limited. For example, the research shows most autistic students are still in segregated settings such as special schools or 'units' in mainstream schools. Despite the recognised importance of appropriate training, less than $4 \%$ could attend this fully 
in work time and half self-funded. The positive attitudes from concerned and dedicated educators trying to understand and support autistic students give a positive message for the prospects of inclusion, but not the lack of resources, suitable conditions and support, knowledge and training that remain despite Polands vision of inclusivity.

Inclusive practice is central to the disability rights agenda worldwide and research shows a social model perspective often leads to more effective and inclusive teaching than a medical model (Stanovich and Jordan, 1998). Developing successful inclusionary practice is a long process that requires commitment, involvement and further research. Thus, evidence is urgently needed on the number of autistic students in mainstream settings in different countries. This includes the factors that affect inclusion and the impacts of inclusion on learning outcomes, academic skills and other success factors which then enable the sharing of good practice across countries.

Overall, greater attention to these issues in research and practice will enable autistic children and young people to benefit from the inclusive educational provision they deserve, give teachers the necessary skills and resources for success, and enable non-disabled children and adults to benefit from diversity and contact with autistic students.

Acknowlegements We would like to thank all the teachers, therapists and other educational professionals who completed questionnaires, as well as everyone who helped us distribute them. Particular thanks are due to Hanna Pasterny for her assistance in both improving the language of the questionnaire and distributing it. We would also like to thank the anonymous reviewers for their helpful comments and suggestions.

\section{References}

Avramidis, E., \& Norwich, B. (2002), "Teachers' attitudes towards integration/inclusion: a review of the literature", European Journal of Special Needs Education, Vol. 17 No. 2, pp.129-147.

Barnes, C. (1994), Disabled People in Britain and Discrimination: a case for antidiscrimination legislation, London, Hurst \& Co.

Buława-Halasz, J. (2015).Możliwości i ograniczenia edukacji właczającej osób autystycznych. In: Bełzy, M. and Prysak. D., Osoba z niepełnosprawnością w drodze do dorosłości., 87-99.

Carnahan, C., Musti-Rao, S., \& Bailey, J. (009), "Promoting active engagement in small group learning experiences for students with autism and significant learning needs", Education and treatment of Children, Vol. 32 No.1, pp. 37-61.

Davidson, J. \& Orsini, M. (eds. 2013), Worlds of Autism: across the spectrum of neurological difference, Minneapolis: University of Minnesota.

DfEE (1997) Excellence for All Children: Meeting Special Educational Needs. London: Department for Education and Employment.

Donnelly, V., \& Watkins, A. (2011). Teacher education for inclusion in Europe. Prospects, 41(3), 341. 
Emam, M. M., \& Farrell, P. (2009). Tensions experienced by teachers and their views of support for pupils with autism spectrum disorders in mainstream schools.

European journal of special needs education, 24(4), 407-422.

European Agency for Special Needs and Inclusive Education (undated,a), 'Agency

Position on Inclusive Education Systems', https://www.european-

agency.org/sites/default/files/PositionPaper-EN.pdf, accessed 02.08.18.

European Agency for Special Needs and Inclusive Education (undated,b),

https://www.european-agency.org/country-information/poland/national-

overview/special-needs-education-within-the-education-system, accessed 01.05.17.

Frederickson, N. \& Cline, T. (2002), Special Educational Needs, Inclusion and

Diversity: a textbook, Maidenhead, Open University Press.

Ganz, J. B., Earles-Vollrath, T. L., Heath, A. K., Parker, R. I., Rispoli, M. J., \& Duran, J. B. (2012), "A meta-analysis of single case research studies on aided augmentative and alternative communication systems with individuals with autism spectrum disorders", Journal of Autism and Developmental Disorders, Vol. 42 No.1, pp. 60-74. Garncarz, A., \& Rybka A. (2012). Terapia i edukacja osób z autyzmem i niepełnosprawnością intelektualną. Próba integracji zagadnień. Sztuka Leczenia, Vol. 3-4, pp. 47-68.

Giangreco, M. F., Edelman, S. W., Luiselli, T. E., \& MacFarland, S. Z. (1997). Helping or hovering? Effects of instructional assistant proximity on students with disabilities.

Exceptional Children, Vol. 64 No. 1, pp. 7-18.

Glashan, L., Mackay, G., \& Grieve, A. (2004), "Teachers' experience of support in the mainstream education of pupils with autism. Improving Schools", Vol.7 No.1, pp. 4960.

Hume, K., Plavnick, J., \& Odom, S.L. (2012), "Promoting task accuracy and independence in students with autism across educational setting through the use of individual work systems", Journal of Autism and Developmental Disorders, Vol.42 No.10, pp. 2084-2099.

Humphrey, N., \& Lewis, S. (2008). Make me normal' The views and experiences of pupils on the autistic spectrum in mainstream secondary schools. Autism, 12(1), 2346.

Joffe. H. \& Yardley, L. (2004), Content and Thematic Analysis, in D.F.Marks \& L.

Yardley (eds, 2004). Research Methods for Health and Clinical Psychology, London: Sage.

Kirkman TW, 1996. Kirkman, T.W. (1996) Statistics to use.

http://www.physics.csbsju.edu/stats/, accessed 6-10.1.10.

Korulska, E. (2013), Funkcjonowanie dzieci z autyzmem w warunkach szkoły ogólnodostępnej,czyli integracja w szkole nieintegracyjnej. In Skibska, J. (Ed.), Konteksty Pedagogiczne 1(1) Spektrum Autyzmu 165-179.

McGregor, E. \& Campbell, E. (2001), "The attitudes of teachers in Scotland to the integration of children with autism into mainstream schools", Autism, Vol. 5 No 2, pp. 189-207.

Martin, N. and Milton, D. (2017), "The inclusion of autistic children”, in Knowles, G. (Ed.), Supporting Inclusive Practice and ensuring opportunity is equal for all, Routledge, Oxon, pp. 111-124.

Morrier, M. J., Hess, K. L., \& Heflin, L. J. (2011). Teacher training for implementation of teaching strategies for students with autism spectrum disorders. Teacher

Education and Special Education, 34(2), 119-132.

Park, M., \& Chitiyo, M. (2011). An examination of teacher attitudes towards children with autism. Journal of Research in Special Educational Needs, 11(1), 70-78. 
Pasterny, H. (2017), Private communication.

Pasterny, H. (2018), Private communication.

Pietrowska, B. (2013) Proaktywne i reaktywne strategie radzenia sobie z trudnymi zachowaniamiu dzieci ze spektrum autyzmu. Studium przypadku. In Skibska, J. (Ed.), Konteksty Pedagogiczne 1(1) Spektrum Autyzmu 193-212

Piskorz-Orgorek, K., Ogorek, S., Cieslinska, A., \& Kostyra, E. (2015), 'Autism in Poland in comparison to other countries". Polish Annals of Medicine, Vol. 22 No.1, pp. 35-40.

Ruble, L. A., \& Dalrymple, N. J. (2002), "Compass a parent-teacher collaborative model for students with autism", Focus on Autism and Other Developmental Disabilities, Vol.17 No. 2, pp. 76-83.

Scheuermann, B., Webber, J., Boutot, E. A., \& Goodwin, M. (2003). Problems with personnel preparation in autism spectrum disorders. Focus on Autism and Other Developmental Disabilities, 18(3), 197-206.

Stanovich, P. J., \& Jordan, A. (1998), "Canadian teachers' and principals' beliefs about inclusive education as predictors of effective teaching in heterogeneous classrooms", The Elementary School Journal, Vol. 98 No.3, pp. 221-238.

Starczewska, A, Hodkinson, A. and Adams, G. (2012), "Conceptions of inclusion and inclusive education: a critical examination of the perspectives and practices of teachers in Poland", Journal of Research in Special Educational Needs, Vol.12 No. 3, pp.162-169.

Teffs, E. E., \& Whitbread, K. M. (2009), "Level of preparation of general education teachers to include students with autism spectrum disorders", Current Issues in Education, Vol.12 No.10.

Touhig, Lord (2013), "Proposed changes to the special educational needs (SEN) system in England", available at: http://www.autism.org.uk/news-and-events/newsfrom-the-nas/changes-tosen.aspx (accessed 1 August 2013).

UN Convention on the Rights of People with Disabilities. (2006), available at: http://www.un.org/disabilities/documents/convention/convention_accessible_pdf.pdf (accessed 1 August 2015).

Urbanovská, E., Kantor, J., \& Růžička, M. (2014), "The education of students with autism spectrum disorders from the teachers' viewpoint-a Czech/Polish comparative study at the secondary education level", Proc Int. Sci. Conf. Society, Integration, Education, 3, pp. 137-151.

Wee, R.Y. (2017), "Countries with the Highest Rates of Autism", available at: http://www.worldatlas.com/articles/countries-with-the-highest-rates-of-autism.html, (accessed 1 May 2017).

Williams, S. K., Johnson, C., \& Sukhodolsky, D. G. (2005), "The role of the school psychologist in the inclusive education of school-age children with autism spectrum disorders", Journal of School Psychology, Vol. 43 No. 2,pp. 117-136. 